I Universidade Federal Rural do Rio de Janeiro (UFRRJ),

Seropédica, RJ, Brasil

saparracho@gmail.com

II Universidade Federal do Rio de Janeiro (UFRJ),

Rio de Janeiro, RJ, Brasil

gui.marcondesss@gmail.com

III Universidade Federal do Rio de Janeiro (UFRJ),

Rio de Janeiro, RJ, Brasil

anacfamiranda@gmail.com

Sabrina Marques Parracho Sant'anna'

Guilherme Marcondes"

Ana Carolina Freire Accorsi Miranda "II

\title{
ARTE E POLÍTICA: A CONSOLIDAÇÃO DA ARTE COMO AGENTE NA ESFERA PÚBLICA ${ }^{1}$
}

Nos últimos anos, movimentos constituídos em cidades brasileiras têm construído uma narrativa em que performances e instalações vêm ganhando espaço dentro e fora das instituições como formas de atuação política, num crescente processo de artificação da esfera pública² e politização da arte. Como argumentaremos, os eventos aqui discutidos parecem associar-se a uma paulatina mudança nos rumos das instituições museais que, conforme mostrado em outras ocasiões (Marcondes, 20I4, 20I5; Miranda, 20I4; Sant'anna, 20II; Miranda \& Sant'anna, 20I4), tem resultado da crescente fusão entre arte e vida.

Em maio de 20I4, o Museu de Arte Contemporânea de Niterói e o Instituto Mesa organizaram o seminário O Sentido do Público na Arte. O evento era parte de projeto, contemplado com o Prêmio Funarte - Io ${ }^{\underline{a}}$ Rede de Encontros nas Artes Visuais - e tinha "como foco a complexidade das interações públicas entre a produção artística contemporânea e a sociedade". As discussões envolviam uma série de debates sobre o papel da arte em sua relação com o público: "não somente a atuação política, mas a arte em sua condição de síntese e mediação entre simbólico e transformação social". ${ }^{3}$

No encerramento das atividades do primeiro dia do evento, o Coletivo No Pasarán projetava, na parede externa da instituição, filme realizado durante a onda de protestos que ganhou o país em junho de 2013. As paredes curvas da praia de Boa Viagem se transformavam em tela e, no silêncio da noite que já caía, os gritos de ordem traziam contra o fundo da paisagem da baía de 
Guanabara um passado recente ainda em movimento. Não só o conteúdo do filme, mas também seu suporte chamava a atenção. A projeção do vídeo na fachada do museu repetia gesto que ganhou espaço a partir das manifestações de 2013 .

Em julho daquele ano, quando da visita do papa ao Brasil, durante a Jornada Mundial da Juventude, o coletivo ProjetAção projetou na parede cega de um edifício no Aterro do Flamengo o trabalho de Marcia X Desenhando com terços. A forma fálica, que havia criado polêmica quando exibida na exposição Arte Erótica, no CCBB em 2006, ganhava proporções vultuosas e ocupava a cidade junto com outras imagens e palavras de ordem. Técnicas de videoarte e de videoinstalação ganhavam a rua e turvavam fronteiras na arena política.

Também no mesmo período, em episódio polêmico, o Coletivo Coiote, em evento realizado em meio à Marcha da Vadias, acionou elementos que muito se aproximam da body art e das performances mais radicais da arte contemporânea. Na manifestação, os artistas - e/ou militantes - introduziram símbolos religiosos em órgãos genitais. Atores do mesmo grupo realizaram, ainda mais recentemente, em junho de 20I4, performance no Polo Universitário de Rio das Ostras da Universidade Federal Fluminense. Na ocasião, a vagina de uma das performers era costurada. O evento extrapolou os muros da academia e ganhou a imprensa. As críticas da sociedade envolvente foram tomadas pela chefia do Departamento de Produção Cultural como forma de censura.

De fato, dando-se a partir de 2013, o surgimento de grupos artivistas é fenômeno crescente. Mais do que os coletivos de arte que ganharam projeção nos anos 2000 com discursos de intervenção na cidade (Miranda, 20I4), o termo tem sido marcado pela estreita relação entre arte e política. A categoria ganhou verbete no Wikipedia (Artivistas, 20I4) e vem designando tanto atitudes de militância política na arte quanto novos coletivos. Tentativas de definição do conceito estão ainda em elaboração. Num esforço recente de conceituação em artigo publicado em Cadernos de Arte e Antropologia, Paulo Raposo (20I5: 3) assim define o termo:

Artivismo é um neologismo conceptual ainda de instável consensualidade quer no campo das ciências sociais, quer no campo das artes. Apela a ligações, tão clássicas como prolixas e polémicas entre arte e política, e estimula os destinos potenciais da arte enquanto ato de resistência e subversão. Pode ser encontrado em intervenções sociais e políticas, produzidas por pessoas ou coletivos, através de estratégias poéticas e performativas [...]. A sua natureza estética e simbólica amplifica, sensibiliza, reflete e interroga temas e situações num dado contexto histórico e social, visando a mudança ou a resistência. Artivismo consolida-se assim como causa e reivindicação social e simultaneamente como ruptura artística - nomeadamente, pela proposição de cenários, paisagens e ecologias alternativas de fruição, de participação e de criação artística.

O surgimento desses fenômenos tem repercutido em exposições e tem sido registrado em publicações recentes - As guerras nos porta-retratos (Provasi, 
20I4), Vocabulário político para processos estéticos (Ribas, 20I4) e Copas: I 2 cidades em tensão (Lima, 20I5) -, sendo também incorporado pelas instituições de arte. Em fevereiro de 20I4, o Sesc-Pompeia, em São Paulo, organizou uma série de oficinas que intitulava Artivismo: criações estéticas para ações políticas. No texto de divulgação, lia-se:

\begin{abstract}
Em junho de 2013 o Brasil viu grandes manifestações populares - em torno de inúmeras reivindicações elas alcançaram um novo grau de cidadania e participação política e um nível inédito de inventividade. Diversos coletivos e grupos de artistas propuseram novas formas de participação e problematização, se valendo de estratégias estéticas e simbólicas para amplificar suas causas.
\end{abstract}

O uso da tecnologia e das novas mídias foi essencial para que esses coletivos se articulassem. A internet veio a ser um instrumento de organização, troca, informação e aprendizado, sem hierarquias e monopólios.

Esse momento de evidência revelou uma vontade crescente, que já ocorre nos últimos dez anos, de união entre a participação política e ações artísticas e culturais, criando um território novo, cheio de experimentação estética e de linguagem. ${ }^{4}$

Com efeito, a temática da arte política parece ter caído no gosto das principais instituições de arte a partir de junho de 20I3. Desde então houve uma sucessão de exposições que abordaram a aproximação entre processos artísticos e ativismo político em importantes eventos de arte no país. De julho a setembro de 20I4, no Rio de Janeiro, a exposição ArteVida, concebida pelos curadores Adriano Pedrosa e Rodrigo Moura, mobilizou quatro espaços expositivos da cidade. A mostra dividiu-se nos seguintes módulos: Corpo (localizada na Casa França-Brasil), Arquivo (Biblioteca Parque Estadual), Política (Museu de Arte Moderna) e Parque (Escola de Artes Visuais do Parque Lage). Embora tivesse enfoque histórico, trazendo obras produzidas entre as décadas de ig50 e I980, incluía discursos de teor político e referia formas de engajamento político e social para tratar da relação entre arte e vida. A exposição se dava num momento em que novas formas de pensar o engajamento político da arte vinham sendo elaboradas e postas em prática. Era, de certo modo, uma fonte de inspiração histórica para os acontecimentos presentes, para a arte que vem sendo feita hoje. Essa exposição pretendia lançar um panorama da arte crítica produzida naquela época, e por mais que não tenha abordado as recentes manifestações artísticas e ativistas, deu grande destaque para a relação de arte e política na produção brasileira.

Também no segundo semestre de 20I4, a 3 I a Bienal de São Paulo reforçou o caminho político que as exposições brasileiras vinham tomando - aspectos dessa grande mostra contribuíram para a problemática da politização da esfera pública aqui abordada, por isso ela será especialmente desenvolvida em um próximo tópico.

Em 20I5, a estreita relação entre arte e política continuou ganhando visibilidade e, além de estar presente em museus como o Museu de Arte do Rio, 
esteve em importantes galerias, como a Anita Schwartz Galeria de Arte, e na Feira Internacional de Arte contemporânea ArtRio. De janeiro a julho de 2015, o Museu de Arte do Rio hospedou em todo seu andar térreo a Zona de Poesia Árida, uma exposição sobre os trabalhos dos coletivos artivistas de São Paulo. Nessa ocasião, muito se discutiu sobre a entrada dessa crítica ao "sistema" numa instituição de arte âncora do projeto de intervenção urbana Porto Maravilha, muitas vezes criticado por ser um processo de gentrificação na cidade do Rio de Janeiro. ${ }^{5}$

Dentro da mesma lógica de crítica política, a exposição Lona, do carioca Gustavo Speridião na Anita Schwartz Galeria de Arte, em junho de 20I5, abordou a crítica institucional e a utilização das imagens dos protestos de junho de 2013 como forma de construção do trabalho. Em plena zona nobre da cidade do Rio de Janeiro, uma galeria de arte expunha uma obra que pintava com letras, que lembram uma pichação das ruas, o dizer “Maldita Burguesia!". Havia também um vídeo sendo exposto e vendido apenas com imagens das "primaveras" que estouraram no mundo nos últimos anos, incluída a de 2013 no Brasil. Mais recentemente, em setembro de 2015 , dentro da ArtRio, podiam-se observar obras que faziam referências a questões políticas e ainda obras que também utilizavam as imagens dos protestos. A galeria portuguesa Filomena Soares vendia a obra Chapa Quente \# I da dupla de artistas Dias \& Riedweg, uma caixa de acrílico com luz interna iluminando fotos das manifestações de junho. Ao lado, um texto de agradecimento aos coletivos de mídia ativistas autores das imagens.

O que estamos argumentando aqui é que talvez o fracasso da fusão arte e vida tão debatido por Peter Bürger (2008: I00) ainda tenha novos desdobramentos. Se "o processo de autonomização da arte corresponderia à ocorrência histórica do desligamento da arte do contexto da práxis vital", Bürger argumenta que as vanguardas de princípios do século XX, em seu processo de crítica à arte pela arte, procurariam fundir arte e vida, fosse por meio da rejeição à autoria, fosse pela crítica ao bom gosto burguês. A crítica ao bom gosto se daria, contudo, por dentro da instituição arte e do mercado, numa falsa superação dessa distinção (Bürger, 2008). Ainda conforme o autor:

Resumindo, os movimentos históricos de vanguarda negam determinações que são
essenciais para arte autônoma: a arte descolada da práxis vital, a produção indivi-
dual e, divorciada desta, a recepção individual. A vanguarda tenciona a superação
da arte autônoma, no sentido de uma transposição para a práxis vital. Tal fato não
ocorreu e, na verdade, nem pode ocorrer na sociedade burguesa a não ser na forma
de falsa superação da arte autônoma (Bürger, 2008: II3).

Mas também, como argumenta Huyssen (I997), o processo de autocrítica da arte, ao colocar dentro das instituições a ironia das vanguardas históricas, derrubaria fronteiras nos museus, levando não só à democratização dos equipamentos expositivos, mas à própria musealização da vida.

Com efeito, Huyssen não escreve no vazio. A partir das décadas de 1960 e I970, alguma coisa parece mudar na maneira de conceber as instituições 
museais, depois da incorporação da crítica das vanguardas à arte pela arte. Não apenas em âmbito nacional, mas num movimento em que as organizações internacionais desempenham papel fundamental, uma nova concepção de difusão de cultura passa a dominar os discursos institucionais. Publicações da Unesco podem ser tomadas como um importante índice dessa mudança.

Realizado pela Unesco em Tóquio em I960, o seminário The Museum as a Cultural Centre in the Development of the Community parece ser a primeira referência ao novo papel a ser atribuído às instituições (Griffing, I963: 4-5). A partir do seminário, o conceito de museu parece passar por nítida transformação naquele período, e, de I970 em diante, a expressão centro cultural passa a ser mais claramente usada na revista Museum como novo modelo de instituição exibitória. Em matéria intitulada "Os museus regionais como centros culturais", Edward P. Alexander, em contundente defesa dos ideais museais americanos, elabora pela primeira vez no periódico a ideia de um centro cultural com "concepção alargada das funções do museu". Associando a imagem dos museus europeus a mausoléus, como antes dele havia feito Adorno (I998: I73), ao remeter o museu à neutralização da cultura, o autor defende os "programas educativos e culturais dos museus americanos, em particular dos museus regionais, os quais são frequentemente autênticos centros sociais e culturais para a coletividade" (Alexander, I970-I97 I: 275) ${ }^{6}$. A ideia de museu como instituição para o grande público começa a desempenhar papel fundamental.

Oito anos mais tarde, também a Museum publicaria com grande destaque a criação do Centro Georges Pompidou em Paris. Reunindo num só espaço as salas exibitórias de exposições de artes plásticas, biblioteca e espaços para performances, o centro deslocaria a tradicional centralidade conferida aos museus de arte e se imporia como novo modelo de instituição de cultura, visando, antes de tudo, estabelecer uma relação de absoluta proximidade com seu público. O desejo de fundar uma instituição para as massas se expressava não só no projeto de Renzo Piano com sua fachada monumental e sua sinalização em neon colorido, mas também no pronunciamento do, então, presidente Georges Pompidou:

Eu desejo ardentemente que Paris possua um centro cultural que seja ao mesmo tempo museu e centro de criação, onde as artes plásticas se avizinhem da música, do cinema, dos livros, da pesquisa audiovisual. O museu não pode ser senão moderno, uma vez que temos o Louvre (Pompidou apud Fradier, I978: 77).

O desejo de ruptura com o museu bastião da alta cultura se fazia evidente. Era preciso atrair o público e romper com a autonomia da arte que a tornava de mais a mais elitista. Se a arte de vanguarda, ao aproximar-se da vida e, portanto, do público, ${ }^{7}$ procurava denunciar o discurso da arte pela arte e subverter o sentido da arte burguesa, acionando o mecanismo da indústria cultural (Bürger, 2008), não por acaso o paradigma lançado a partir do Georges Pompidou parece refazer o percurso da arte moderna e, ao se aproximar da 
vida, contribuir para uma sociedade do espetáculo. Com efeito, a partir de finais dos anos I970, o discurso das vanguardas passava a ditar as cartas também no interior dos museus.

Diretor fundador do Centro Georges Pompidou, Pontus Hultén constitui peça-chave na mudança de paradigma que passa a ordenar as estratégias das instituições museais e transformar os conservadores de museus em curadores de exposições. Responsável por transformar Estocolmo numa capital das artes nos anos I960, Hultén, numa relação muito próxima com as vanguardas que lhe eram contemporâneas, introduziria nas instituições de arte por que passou a ideia de participação do público e o foco nos jovens artistas e na experimentação. Em entrevista a Ulrich Obrist (2010: 65), numa rememoração do processo de fundação do Centro Georges Pompidou, de que foi o primeiro diretor, ele diria:

Em I967, trabalhamos na Casa de Cultura para a cidade de Estocolmo. A participação do público era para ser mais direta, mais intensa e mais interativa que antes, isto é, queríamos desenvolver seminários, nos quais o público pudesse participar diretamente; pudesse, por exemplo, discutir como algo novo estava sendo tratado pela imprensa; eram locais para exercer uma crítica da vida cotidiana. Era para ser um Centro Pompidou mais revolucionário, numa cidade muito menor que Paris. O Beaubourg também é um produto de I968: 1968 visto por Georges Pompidou.

O processo de ruptura com os museus como bastiões da alta cultura que passam a se abrir para o grande público e, fazendo uso do discurso crítico das vanguardas, passam a colocar em xeque critérios estabelecidos pela autonomia da arte ocupa, com efeito, grande parte das reflexões sobre instituições museais na contemporaneidade. Iniciado nos idos dos anos I96o e levado a efeito a partir dos anos I970, o processo se deu também no Brasil e parece vir realmente tendo efetividade no mundo da vida contemporânea.

O que estamos argumentando, no entanto, é que, se o processo de crítica à instituição museal, em curso desde a exibição de A Fonte, de Duchamp, teve profundas consequências para as instituições museais, como já chamou a atenção Vera Zolberg (Zolberg \& Cherbo, I997) em Outsider Art, o que se verifica, a partir de 2013 é um novo movimento de transformação da experiência artística em elemento político. ${ }^{8}$

Se Andrea Fraser (2005) tem razão ao expandir o conceito de Bürger e chamar a atenção para uma instituição de arte que está incorporada à vida social, o fenômeno, ora em curso, parece ter pouca relação com seu Museum Highlights e a crítica institucional, embora, evidentemente, não deixe de ser também consequência da explosão de fronteiras museais levadas a efeito desde as vanguardas históricas (Huyssen, I997). Em I989, Andrea Fraser executaria a performance Museum Highlights no Philadelphia Museum. No papel de docente fictícia, a artista parodiava as visitas guiadas aos museus, e, além da história da instituição, descrevia os banheiros, a chapelaria, a loja e os sinais de saída. Ao longo da performance, que marcou sua trajetória, Fraser incluía comentários 
sobre política e sociedade. Em 2005, ela publica em Artforum importante autorreflexão sobre a institucionalização da crítica institucional:

Se, como coloca Bürger, a autocrítica da vanguarda histórica pretendia "a abolição da arte autônoma" e sua integração "na prática vital", ela falhou tanto em seus objetivos quanto em suas estratégias. Contudo, a própria institucionalização que marcou esse fracasso se tornou condição da crítica institucional. Ao reconhecer o fracasso e suas consequências, a crítica institucional se afastou dos esforços crescentemente de máfé das neovanguardas que visavam desmontar a instituição de arte ou dela escapar. Em seu lugar, passou a almejar defender a própria instituição que a institucionalização da autocrítica da vanguarda potencialmente criou: a instituição da crítica. E é possível que essa própria institucionalização permita que a crítica institucional julgue a instituição de arte contra os clamores críticos de seu discurso legitimador, contra sua autorrepresentação como espaço de resistência e contestação, e contra mitologias de radicalidade e revolução simbólica (tradução dos autores).

Se para Bürger, a entrada da crítica nos museus seria sua pacificação e derrota, Fraser argumenta que haveria espaço para uma instituição crítica. Guardadas as devidas proporções, mais que remeter às performances recentes de Fraser, o momento aqui discutido parece reencenar outros momentos remetendo tanto às barricadas de 1968 quanto às experiências radicais de ruptura institucional que se seguiram: pensamos aqui em Pontus Hultén, ${ }^{9}$ mas também em Walter Zanini ${ }^{\text {Io }}$ e Frederico Moraes. ${ }^{\text {II }}$ A história se repete (repete?), mas o Georges Pompidou já foi construído, e seu modelo de centro cultural deveras criticado.

O processo não vem de hoje, mas essas ações de turvamento foram sendo observadas, no Brasil, principalmente após as manifestações de junho de 20I3. Poder-se-iam aqui enumerar vários eventos de natureza similar que ocorreram tanto nos espaços públicos quanto nos privados. Neles, ficaram evidentes as transformações nas poéticas utilizadas tanto por artistas quanto por manifestantes com o intuito de se expressar e que permitem que Cristina Ribas (20I4: 7) - artista, pesquisadora e curadora - pergunte: "Como falar dos processos estéticos que nos transformam em nossos cruzamentos com a política?".

\section{INSTITUIÇÕES E POLÍTICAS PÚBLICAS - ANTES DE 2013}

Do ponto de vista institucional, museus, centros culturais e espaços expositivos parecem vir sendo chamados a responder a essas novas demandas.

Alvo preferencial da crítica das vanguardas que, desde Marinetti, pretendiam queimar bibliotecas e museus, espaços expositivos vêm há tempos enfrentando a crítica às instituições. Se A Fonte de Duchamp é a porta de entrada da crítica no interior das instituições, nos anos I990, Andrea Fraser e a crítica institucional ganharam proeminência repercutindo em trabalhos que invadiram de ironia espaços expositivos. Nos últimos anos, no entanto, a linha de tensão entre arte, política e instituições parece vir se abrindo para outros atores sociais. 
Em 2008, um grupo de pichadores invadiu a Bienal de São Paulo, inscrevendo em suas paredes tags e palavras de ordem, num gesto que culminou com a prisão de Caroline Pivetta da Mota e ganhou notoriedade na imprensa. Dois anos depois, na nova edição do certame, o grupo ganhou espaço no interior da Bienal, apresentando o trabalho Pixação SP. Segundo Agnaldo Farias, curador da Bienal:

Eles nos procuraram dizendo o seguinte: "A Bienal vai ser sobre arte e política e nosso trabalho é político, queremos discutir com vocês." Nós também achamos o trabalho deles político, se é artístico não sei. Não estou preocupado em fazer esse julgamento. A proposta foi apresentarmos o trabalho deles como documento. Não existe picho consentido. Eles vão apresentar slideshows e fotos (Paola, 2010).

A versão de Djan Ivson era outra. Segundo ele, o convite fora feito pelo Ministério da Cultura, pasta ocupada então por Juca Ferreira. ${ }^{12} \mathrm{O}$ grupo fora procurado após os ataques de 2008 e vinha mantendo o diálogo "porque a nossa luta na realidade é de legitimar a pichação como cultura brasileira, mas sem tirar nada da essência dela". ${ }^{\text {I3 }}$

De fato, ainda em dezembro de 2008, Juca Ferreira lançava manifesto sobre o caso da prisão de Caroline Pivetta, enfatizava o diálogo e a produção de cultura de um ponto de vista da periferia. Segundo ele, "a agressividade simbólica ainda aparece como 'alternativa', de forma ilusória, a estes jovens submetidos a um cotidiano de violência, e passa a ser a 'compensação cultural' por vezes a seu alcance para fugir do crime ou da marginalidade de fato". ${ }^{14}$

Interpretações divergentes têm, contudo, gerado polêmica. Em entrevista publicada antes da abertura da Bienal, em 2010, Djan Ivson dizia: "Se a sociedade está interessada em ouvir a gente, estaremos lá para falar. Sem querer apaziguar, sem querer dar uma de bonzinho" (De Lucca, 2010). O episódio do picho não consentido culminou, em 25 de setembro, na abertura da Bienal ao público, com a pichação da obra de Nuno Ramos. O caso foi seguido por nota de repúdio da instituição, que classificou o gesto como ato de vandalismo e violência.

Em 20I2, novamente convidado a participar de uma Bienal, agora em Berlim, o grupo Pixadores SP se envolveu em nova polêmica, expandindo os limites previamente determinados pela instituição e escalando paredes da igreja em que acontecia o evento para deixar ali suas mensagens. A discussão entre membros do grupo e o curador terminou em agressões e banhos de tinta.

O episódio, embora longo, descortina parte do emaranhado de novos atores que ganharam protagonismo nas duas últimas décadas e algumas das consequências não previstas da ação. O apoio de Juca Ferreira em 2008 ao Pixadores SP, ao contrário do que pode parecer, não se ancorava numa tomada de posição isolada do ministro recém-empossado, mas vinha de uma diretiva de políticas do Ministério que, desde Gilberto Gil, vinha dando novo protagonismo ao MinC. 
Em 2003, a participação de Gilberto Gil e Claudio Prado no festival Mídia Tática Brasil abriu o ministério da Cultura a formas de ativismo em rede e ao uso da tecnologia da informação para descentralizar a produção de cultura. Ao lado do software livre e do creative commons, a criação de pontos de cultura colocou em evidência novos caminhos para a visibilidade de setores marginalizados pela alta cultura, mas também abriu caminho para pensar redes alternativas de visibilização e produção de bens de cultura. ${ }^{15}$

De fato, se Anne Cauquelin (2005) chama a atenção para a substituição de um registro de mercado por um registro de comunicação, a ênfase na democratização do acesso à tecnologia tem-se desdobrado, de um lado, na crítica à arte mainstream e, de outro, no sucesso que se mede pelo número de visualizações. Não por acaso, a circulação crescente dos situacionistas de Guy Débord - tema de exposição da Biblioteca Nacional Francesa em 2013 - e, sobretudo, das Zonas Autônomas Temporárias, de Hakim Bey ${ }^{16}$ - cuja primeira edição em português está esgotada, mas que dispõe de digitalizações disponíveis na rede -, tem redundado, mundo afora, em ações pontuais capazes de repercutir com vigor nas instituições museais e espaços expositivos. Se os precursores da performance e das intervenções urbanas já operavam na lógica de desdobrar, do evento único, produtos capazes de entrar no mercado, ${ }^{17}$ o que se verifica aqui é o uso subterrâneo de estratégias similares visando, mais do que à crítica institucional, a posições políticas. Se é verdade que Cildo Meireles com suas Inserções em Circuitos Ideológicos ou Antonio Manuel em Eis o Saldo são claros exemplos do que se poderia chamar de arte engajada desde a década de I960, o que tem atualmente chamado a atenção é o uso de novos mecanismos que efetivamente misturam manifestações políticas e arte, e turvam fronteiras entre artistas e ativistas. Performances em manifestações de rua e a dissolução da autoria em obras de arte que incorporam ações políticas nos mais diferentes meios (Miranda, 20I6; Cordeiro, 20I5) são alguns dos novos mecanismos que se tornaram recorrentes nos últimos anos.

Resta, portanto, entender de que modo o surgimento de novas sensibilidades tem repercutido no sistema de arte, para usar o termo de Peter Bürger (2008).

\section{A BIENAL DO ARTIVISMO}

Pensando sobre a (inter-)relação entre arte e política, é impossível não mencionar a 3 I a Bienal de Arte de São Paulo ocorrida de setembro a dezembro de 20I4. Ao caminhar pelo Parque Ibirapuera com destino ao Pavilhão da Bienal, era possível notar que o clima de expectativa por se estar indo assistir a uma Bienal de Arte se misturava com o impacto daquilo que se ia revelando aos poucos. E, ao adentrar o prédio, uma dúvida permanecia: tratava-se de arte ou de militância política? Inúmeras discussões nos corredores da mostra e nos veículos de comunicação especializados voltaram-se para a compreensão da proposta daquela Bienal de São Paulo, que já era encarada como a mais política de todas, ficando conhecida como a Bienal que uniu arte e ativismo. ${ }^{18}$ 
Olhando em retrospecto, os eventos políticos ocorridos no Brasil por conta das manifestações políticas de junho de 20 I 3 podem trazer pistas para o entendimento da necessidade de construção de uma bienal de arte com forte cunho político.

Partindo do título da mostra, Como (...) coisas que não existem, é possível encontrar, no site oficial da bienal, uma série de palavras-chave que decodificam os interesses daqueles que a propuseram. Algumas categorias chamam especial atenção: conflito, apropriação, transformação, virada, luta, entre outras. Sendo o tom dos textos o de um quase manifesto - mas não um manifesto como aquele de André Breton e Leon Trotsky, que visava a uma arte revolucionária independente -, o texto da $3 \mathrm{I}$ a Bienal reivindica o empoderamento dos indivíduos, visa à possibilidade de que as pessoas se apropriem de suas próprias vidas para, assim, transformar a arte e o mundo que as circundam. Essa concepção que enfatiza o empoderamento dos indivíduos dialoga com a noção de heterotopias, um conceito extraído da teoria foucaltiana que revela a potência das revoluções cotidianas. Esse arcabouço teórico é a principal base do atual discurso do campo da arte contemporânea.

Em seu texto curatorial apresentado no site e nos guias daquela edição, os curadores avisavam que as propostas dos projetos girariam em torno de quatro questões: coletividade, conflito, imaginação e transformação.

A luta das minorias contra um poder que as subjuga, com vistas à transformação da arte e da sociedade, foi de fato o foco de, talvez, a maior parte dos trabalhos que compuseram a exposição. De acordo com análise qualitativa em etnografia da exposição e análise do catálogo da mostra, mais de 50\% das obras exibidas faziam referência explícita a temas presentes no domínio da negociação política da esfera pública. Os conflitos que envolvem racismo, machismo, gentrificação e homofobia estão entre as práticas sociais questionadas por meio dos trabalhos apresentados. Do mesmo modo, muitas das demandas sociais apresentadas pelos manifestantes de junho de 2013 também serviram de inspiração para os debates estético-políticos da 3 I a Bienal; dos controversos blackblocs, trazidos pela obra Não é sobre sapatos, de Gabriel Mascaro, às questões de gênero, que ganharam visibilidade, nesse caso, por exemplo, mediante Linha da Vida/Museu Travesti do Peru, de Giuseppe Campuzano.

Os discursos políticos minoritários apresentados não eram apenas aqueles dos expositores brasileiros. As reivindicações por espaço, igualdade, equidade e visibilidade foram associadas às de outros agentes, oriundos de outros países. Relacionando o Brasil, país-sede da mostra, com outros contextos, por meio das lutas de grupos sociais minoritários, que tiveram suas pautas apropriadas e estetizadas por artistas visuais, a 3 I $^{\text {a }}$ Bienal de Arte de São Paulo, de fato, mostrou-se uma Bienal Artivista par excellence.

Com efeito, falar dessa bienal requer falar também de coletividade, além do citado conflito. Essa edição se destacou por ter uma equipe curatorial com 
cinco curadores estrangeiros, ou seja, uma curadoria coletiva, em que não houve um curador chefe. A construção da proposta curatorial dessa edição foi sendo acompanhada e construída sob o olhar e a avaliação de i5 participantes que se reuniram em encontros abertos ao público realizados em algumas cidades brasileiras, e outras pelo mundo, mensalmente de outubro de 2013 a novembro de 20I4, período que antecedia a mostra:

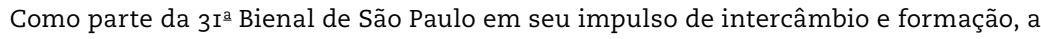
equipe de curadores (Charles Esche, Galit Eilat, Nuria Enguita Mayo, Pablo Lafuente e Oren Sagiv) programou uma série de encontros abertos com profissionais do meio artístico e com o público geral. A ideia é que os encontros funcionem simultaneamente como ferramenta de pesquisa e como forma de avaliação crítica do processo curatorial, envolvendo artistas, críticos, curadores, estudantes e demais interessados na organização da exposição. ${ }^{19}$

A máxima da construção colaborativa foi enfatizada também por parte do programa educativo dessa bienal. O material nela distribuído foi pensado a partir do debate com alguns profissionais de educação:

Na última semana de novembro, o Educativo Bienal iniciou a produção do Material Educativo em um processo colaborativo inédito. Pela primeira vez, foram convidadas cerca de 30 pessoas, entre professores, educadores, coordenadores pedagógicos e equipe interna do Educativo para elaborar o conteúdo do material. ${ }^{20}$

Lendo-se o relato do encontro aberto do Rio de Janeiro proposto pela curadoria dessa edição do evento, notam-se o caráter transgressor e o desejo de rompimento com as bienais anteriores, faceta que também é encontrada no discurso por meio de expressões tais como "inédito" e "pela primeira vez" localizadas na passagem citada.

Primeiramente, percebe-se nesse relato um afastamento da ideia de um tema para essa bienal; a curadoria propõe em seu lugar "uma proposta metodológica que implica apropriar-se da institucionalidade da Bienal como ferramenta para desencadear processos coletivos". ${ }^{21}$ Destaca-se nessa fala também a intenção dos curadores de coletivizar a Bienal enquanto processo, propondo a incorporação emancipadora do público que culmina, mas não se esgota, na exposição de arte. Diz-se buscar a construção coletiva de um novo argumento, por meio da imaginação - um dos quatro vocábulos utilizados como pilares para a curadoria. O discurso da curadoria da Bienal, interpretado por esse relato publicado no próprio site do evento, afirma a premissa da negação da autonomia da arte por assumir-se uma posição de influência sobre o público com medidas efetivamente transformadoras - vide o local da educação no centro das propostas da 3 I $^{\mathrm{a}}$ Bienal. O discurso da crise de representatividade desencadeadora dos protestos que eclodiram a partir de junho de 20 I 3 é também estopim para a metodologia dessa Bienal, segundo seus curadores. No guia de apresentação da mostra, há passagem especialmente digna de nota. O texto destaca que a sociedade estaria passando por um momento de crise que desencadearia uma "virada", e por isso a 
Bienal também seguia esse fluxo. Momento de virada diferente da virada moderna apoiada na noção de progresso, um momento de virada não delimitado, quando não se sabe ao certo aonde se chegará. "Esse estado de virada é nossa condição contemporânea e, por conseguinte, a condição desta 3 Iํㅡㄹienal." ${ }^{22}$

Contando com mais de roo participantes de 34 nacionalidades com 84 projetos, essa Bienal teve como marca a colaboração. Um visitante atento poderia facilmente perceber o grande número de obras de artistas realizadas em colaboração - entre os próprios artistas ou entre artistas e ativistas -, e também o grande número de coletivos de arte. Coincidência ou não, no site oficial dessa $3 \mathrm{I}^{\text {a }}$ Bienal de São Paulo, pela primeira vez, não se encontravam as palavras "artistas" ou "obras" e sim "participantes e projetos". Assim, percebe-se um discurso que transpassa movimentos de incorporação do público por meio de obras-processos que envolvem mais do que os artistas convidados, membros de movimentos sociais e idealizadores de projetos.

Esse processo de incorporação de não artistas para dentro de bienais pode ser observado nos últimos anos em outras bienais ao redor do mundo, como no caso da 55 a Bienal de Veneza, a "Bienal do impossível", ocorrida em

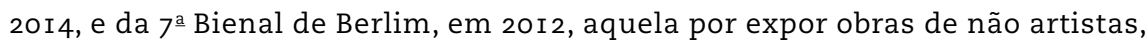
como Carl Gustav Jung, esta por expor trabalhos de ativistas, como o Occupy museum, e dos pichadores de São Paulo.

No texto curatorial da 7 a Bienal de Berlim, observa-se um tom de ruptura com as demais edições do evento, abordando uma proposta bastante parecida com a da Bienal de São Paulo de 20I4. Os movimentos sociais sendo incorporados como obra, tais como o movimento americano Occupy Museum em Berlim e as ativistas bolivianas do Mujeres Creando em São Paulo, são sinais de que a arte de hoje realmente está passando por processo diferente de outros momentos de sua história, politizando a esfera artística e trazendo para lutas políticas elementos estéticos. Esse processo, embora obviamente impactado por processos externos ao campo da arte, tem também no interior de suas instituições fatores que vêm levando a um profundo movimento de autocrítica no sistema de arte. Nesse sentido, uma análise mais detida sobre a figura do curador e sobre os processos de julgamento da arte parece ser fundamental para entender a permeabilidade do campo a questões mais amplas da sociedade envolvente.

\section{A ARTIFICAÇÃo DA ESFERA PÚBLICA E OS NOVOS ESPAÇOS EXPOSITIVOS}

O processo de incorporação de manifestações políticas como práticas artísticas em espaços expositivos, guardadas as devidas proporções, em muito remete ao processo de artificação discutido por Heinich e Shapiro (2013). No entanto, mais do que conferir status de arte a objetos antes não artísticos, turvando as fronteiras entre alta e baixa cultura (Zolberg, 2009), os objetos, performances e manifestações, aqui descritos, têm, contidos em si, também o germe da crítica às 
instituições museais e retomam, em outra chave, as discussões de Bürger e Huyssen. Se a crítica das vanguardas teria levado nos anos I960-I970 à criação dos centros culturais, resta saber que impacto o novo fenômeno vem tendo sobre as instituições contemporâneas.

Não por acaso, a inauguração do Museu de Arte do Rio, em março de 2013, parece antecipar a tensão que vem marcando a relação entre espaços expositivos e novas manifestações artísticas caracterizadas pela politização da arte. Se a festa de abertura da instituição contava com a presença ilustre da presidente Dilma Roussef, da ministra da Cultura Marta Suplicy, do prefeito Eduardo Paes e do governador Sérgio Cabral, do lado de fora, palavras de ordem antecipavam os movimentos sociais mais amplos que viriam meses mais tarde a denunciar a espetacularização, falsas imagens e a impossibilidade do consenso em torno de um futuro promissor, fosse ele simbolizado por copas, olimpíadas ou museus do amanhã.

O MAR, construído em área de interesse para promoção de um polo de economia criativa no Rio de Janeiro, foi inaugurado com a mostra $\mathrm{O}$ abrigo e o terreno, incorporando, para refletir sobre a cidade, categorias que estavam no bojo da crítica à instituição. Segundo o fôlder de divulgação, "a mostra problematiza a propriedade, a posse e o usufruto dos espaços sociais - o terreno - e os modos como produzem política e subjetividade, do direito à habitação ao desejo de abrigo". ${ }^{23}$

Ainda que a curadoria deglutisse na exposição a crítica à gentrificação, a sede não se podia suprimir. Nesse caso, o convite ao diálogo não poderia ser, para alguns grupos de atores sociais, senão pura imagem, falsa consciência, ideologia. Dizia Barbara Szaniecki (2013: 6):

O Bloco Reciclato, entre apitaço e panelaço, afirmava "o sertão não vai virar MAR" e perguntava como artistas e coletivos de artistas que circularam com os movimentos pela moradia podiam, agora, expor os resultados no Museu que é um símbolo da gentrificação. É possível mostrar seu trabalho sem ser "capturado" pelo dispositivo MARítimo? É possível "criativos" atuarem criticamente - "dentro" e "contra" - esse MAR que coroa um projeto de cidade de expulsão dos pobres? É possível que o próprio MAR atue "dentro" e "contra" esse projeto de cidade? É possível criar outras institucionalizações da arte que não modulem por meio de seus sutis dispositivos a crítica constituinte da cidadania?

A tensão, já expressa na difícil relação entre Pixadores SP e Bienal de São Paulo, vinha mais uma vez à tona. Se uma autoconsciência crítica de curadores tem levado a certa permeabilidade dos espaços expositivos a esses novos agentes, a natural acusação de cooptação, apaziguamento, ideologia tem colocado limites a uma síntese interna aos museus e centros culturais. Se, conforme argumentado em outras ocasiões, tensões como essas levaram à criação de centros culturais a partir de I968 (Sant'anna, 2012), outros caminhos para uma nova síntese parecem vir sendo construídos. 
De fato, a criação de novos espaços de debate vem emergindo com alguma visibilidade na cidade. A partir de 2013, por exemplo, a antiga Casa Nuvem, então recém-fundada, lançou às quintas-feiras o ateliê dissidências criativas. Em sua página no Facebook, o ateliê assim se definia:

Espaço de debate e ação. Espaço de uma arte que REAL-liza no aqui e no agora, que se alimenta e alimenta movimentos sociais e propõe outros tipos de dissidências, fugindo dos clássicos rituais de protesto.

No atelier criamos materiais diversos de insurgência poética: material gráfico, sonoro, vídeo, contra-publicidade, traquitanas, roupas, performances, etc.

É um espaço coletivo para experimentar, praticar e espalhar o tesão de fazer e pensar política. Lugar de convergência, de troca de ideias, de mistura de cada um de nós e dos vários coletivos artivistas e movimentos sociais da cidade. ${ }^{24}$

Criado em 20 I I, também o Espaço Atemporal parece vir se consolidando como lugar de novas práticas para novas sensibilidades. Em I 2 de outubro de 20I4, a Revista de Domingo, de O Globo, anunciava livro do Atemporal. Publicado na sessão "Sei lá, mil coisas", o breve relato da colunista Carolina Ribeiro (2014) dava conta das novas práticas ali adotadas.

Antonio Bokel não chama de curadoria o processo de seleção dos artistas que participam do livro 'Atemporal' (Réptil), que reúne trabalhos de ig representantes das artes plásticas [...]

- Não sou curador. Prefiro chamar de 'agregadoria'. É um processo intuitivo que parte de encontros com artistas. Tem muita gente que descobri na internet, é uma rede que vai se formando - conta Bokel.

Ele também não usa a palavra galeria para definir o local do evento:

- A ideia é que não seja um cubo branco, e o foco também não é a comercialização. Chamo de ocupação. O livro é resultado de um projeto homônimo que existe desde 20II, com o objetivo de reunir nomes badalados e novos no mercado, para fazer as tais ocupações:

É um projeto que tem três pilares: internet, livro (que contou com um crowdfunding) e galeria.

Espaços com propostas colaborativas dessa espécie têm-se proliferado no Rio de Janeiro nos últimos anos com o intuito de expor a arte política e/ou coletiva que vem sendo produzida. No entanto, cada uma dessas "casas" tem suas características próprias e, apesar de se autodenominar colaborativa possui diferentes relações com os artistas e seus curadores. Em um casarão antes abandonado e hoje ocupado na Lapa vivem dez jovens artistas e estudantes de cinema que produzem, coletivamente, desenhos, fotografias, zines e filmes, e formam o coletivo Osso Osso, que já ganhou prêmio com um curta-metragem e em breve deve vender seus produtos via seu site na internet, ainda que não esteja propriamente inserido no mercado de arte. Já o Espaço Olho da Rua em Botafogo, 
idealizado e coordenado pelo artista Antonio Breves, se caracteriza como uma loja de produtos com design sustentável, uma galeria de arte, um café-bistrô e um espaço multiuso, reservado a cursos, workshops e oficinas. Mas também se descreve em sua página no Facebook como "um local de compartilhamento de ideias, reservando à criatividade e à dinâmica colaborativa o papel de protagonistas na nova ordem econômica. É um espaço imerso em sinergia cidadã, que não prescinde do zelo às iniciativas socioculturais e onde a estética e a arquitetura urbanas dão à matéria bruta o status de arte". Ainda afirma: "declaramos que o Espaço Olho da Rua foi criado por nós mas que é e continuará sendo construído por todos". Em exposição coletiva recente intitulada URBANICIDADE, informa que "marcou também uma parceria colaborativa entre o Olho da Rua e conceituadas galerias de arte, que ao longo das últimas décadas tem ajudado a formar um importante mercado de apreciadores e colecionadores da chamada arte urbana". ${ }^{25}$ A coletiva apresentou trabalhos recentes e antigos de Vik Muniz, Virginia de Medeiros, Raul Mourão, Milton Machado, Marcos Chaves, Felipe Morozini, Guilherme Callegari, Daniel Melim, Coletivo Bijari, Cao Guimarães, Antonio Breves e Antonio Bokel. Ou seja, o Olho da Rua é um espaço que dialoga com o mercado de arte e artistas consagrados, mas que também, em outras ocasiões, mostrou abrir oportunidades para jovens artistas.

Além desses poderíamos enumerar vários espaços de norte a sul na cidade do Rio de Janeiro que também possuem caráter colaborativo. ${ }^{26} \mathrm{Algo}$, porém, que merece também ser destacado é a maneira como o espaço público está sendo ocupado e tomado como um lugar de produção cultural, e não só por um curto espaço de tempo e sem muitos recursos materiais, como as performances de artistas visuais citadas no início deste texto. Há a emergência de coletivos como o Sarau do Escritório ou o coletivo SerHurbano, que contam com iniciativas próprias ou com o crowdfunding (a atual plataforma de se juntar dinheiro via internet), uma verdadeira estrutura própria para realizar exposições de arte, apresentações, musicais e saraus, ou seja, manifestações artísticas em geral. E vêm assim ressignificando e trazendo novos sentidos para as noções de curadoria e espaço expositivo.

\section{CONSIDERAÇÕES FINAIS}

A aproximação entre arte e crítica política da qual tratamos diz respeito a um processo recente que tem buscado, na ação coletiva e no diálogo com as questões do dia a dia das minorias sociais, políticas, econômicas e culturais, trazer para a esfera da arte discussões eminentemente políticas. A proposta de muitos grupos parece ser discutir as mazelas sociais a partir das linguagens artísticas. Trata-se, de fato, da politização da esfera da arte. E, ao que tudo indica, no discurso dos atores sociais, a sociedade civil não mais recebe relatos do que acontece no universo da arte, ela é convidada a participar e dialogar com as obras de arte, os artistas e os curadores, não apenas como público observador ou tema 
dos trabalhos, mas como coautor. Se nos anos I940, Benjamin havia diagnosticado a "atrofia do parlamento" 27 e Hannah Arendt falava, nos anos I950, da substituição da esfera pública pela predominância da esfera social, ${ }^{28}$ o que procuramos argumentar aqui é que parece ocorrer neste momento o surgimento de grupos de interesse organizados que rompem com esse processo.

Se ao fim dos anos I960 a crítica das vanguardas se impôs sobre os museus, abrindo os ditos mausoléus ao discurso democratizante dos centros culturais, críticos desse processo têm chamado a atenção para o surgimento de museus de culturas de massas, ao longo das duas últimas décadas do século XX (Huyssen, I997). O que argumentamos com este artigo é que, ao longo do último triênio, a difusão desse diagnóstico no Brasil tem apontado para novas críticas e novos desdobramentos. Se, como diz Hannah Arendt (2000: 390), as massas são informes e "devem ser conquistadas por meio da propaganda", os tempos são outros, e a organização de grupos de interesse, via redes sociais, vem colocando em xeque tradicionais mecanismos de cultura de massas e junto com eles museus e centros culturais. Assim, o que procuramos mostrar é que nesta segunda década do século XXI novas instituições e arranjos institucionais têm surgido no bojo de uma nova configuração política que incide com vigor sobre o campo da arte, colocando em xeque sua autonomia.

Coletivização: ato ou efeito de coletivizar-se. Esse termo em suas várias declinações é a palavra de ordem do momento. E, assim, artistas se reúnem em coletivos a fim de dar voz a suas poéticas e das minorias, e curadores se unem em uma das principais mostras de arte do país para discutir os problemas sociais de forma estética. De fato, produzir coletivamente é o mote da vez. Não é possível dizer se essa tendência terá um longo futuro, mas atualmente ela está presente com toda a potência, efetivamente modificando a relação de instituições com o público e criando novos arranjos institucionais. Para além desse processo, na noção de coletividade empregada hoje no mundo da arte, parece, no entanto, haver o desejo de subversão da lógica de dominação presente não apenas na esfera da arte, mas em todos os âmbitos da vida social. O desejo de transformação das regras socialmente vigentes é patente. E, no bojo dessas contestações, a arte tem sido encarada como a viabilizadora de discursos de teor político que, se não buscam a transformação social, ao menos a discutem. Assim, num processo de mão dupla, movimentos sociais e grupos organizados da sociedade civil têm buscado na arte elementos para dar visibilidade a discursos de contestação. Se a esfera artística tem aberto espaço para discursos políticos, como o fez em outros momentos, um novo processo parece vir redundando, por sua vez, numa artificação da esfera pública. De um lado, quando o sucesso se mede pela circulação de imagens, a arte permite destaque na multidão. De outro, quando mediadores institucionalizados parecem estar em crise (Silva et al., 20I5), o uso expressivo da linguagem talvez possa dar voz a insatisfações ainda não discursivamente formuladas. Se nos últimos anos, a 
cultura ganhou proeminência na explicação sociológica das relações sociais correspondendo a seu crescente peso na sociedade contemporânea (Morató, 20II), e ganhou também espaço cada vez maior na formulação de políticas para a cidade (Sassen, 2005), talvez seja natural que ela também se dissemine, ganhando proeminência na formulação de contradiscursos e contrapoder.

Contudo, se o contradiscurso das décadas de ig6o e i 970 culminou na crítica aos museus de cultura de massas, a partir dos anos I980 e I990 as consequências desse processo beiram ainda o imponderável. A se repetir a história, é de esperar que o movimento seja deglutido em novos arranjos institucionais. Seja como for, como lembra Huyssen, a deglutição também implica descontinuidade.

Recebido em I6/05/20I6 | Revisto em 9/I I/20I6 | Aprovado em I9/oI/20I7

Sabrina Marques Parracho Sant'anna é doutora (2008) e mestre (2004) em sociologia e antropologia pela Universidade Federal do Rio de Janeiro, graduada (200I) em ciências sociais pela mesma instituição, em que atualmente é pesquisadora associada; e professora adjunta da Universidade Federal Rural do Rio de Janeiro.

Guilherme Marcondes é doutorando e mestre pelo Programa de PósGraduação em Sociologia e Antropologia da Universidade Federal do Rio de Janeiro, graduado em ciências sociais pela mesma universidade, de cujo Núcleo de Pesquisa em Sociologia da Cultura é pesquisador. É assistente de pesquisa na Fundação Getulio Vargas no projeto: Difusão e Educação Patrimonial do Acervo Histórico do CPDOC.

Ana Carolina Freire Accorsi Miranda é doutoranda do Programa de Pós-Graduação em Sociologia e Antropologia da Universidade Federal do Rio de Janeiro, mestre pelo Programa de Pós-Graduação em Ciências Sociais da Universidade Federal Rural do Rio de Janeiro, graduada em ciências sociais pela Universidade Federal Fluminense; e pesquisadora do Núcleo de Pesquisa em Sociologia da Cultura da Universidade Federal do Rio de Janeiro. 


\section{NOTAS}

I Este artigo é resultado de pesquisa realizada com apoio do CNPq (Edital Universal) e Faperj (Jovem Cientista do Nosso Estado).

2 A respeito da noção de esfera pública ver Habermas, I984.

3 Cf. material de divulgação do Seminário Nacional o Sentido do Público na Arte. Disponível em: http://www.macniteroi.com.br/?p=I748. Acesso em: I5 abr. 2015.

4 Disponível em <http://oficinas.sescsp.org.br/evento/show/ artivismo-criacoes-esteticas-para-acoes-politicas-vagasdisponiveis $>$. Acesso em 3 jul. 2015

5 Vale ressaltar que esse museu possui uma relação particular com coletivos artísticos desde sua inauguração - e que será discutida posteriormente -, relação que envolve o reconhecimento de alguns desses grupos por essa instituição e ao mesmo tempo causa repúdio a outros coletivos.

6 Para um balanço histórico das questões que envolvem os centros culturais, consultar Dabul, 2008.

7 O mote de aproximação entre arte e vida é recorrente no discurso das vanguardas históricas e serviu tanto para depreciar as instituições museais como aquelas que apartam os objetos de seu uso no mundo da vida quanto para defender uma estetização do real que passava pelo design construtivo. A esse respeito, ver, por exemplo, Fabbrini (2013).

8 O processo, é claro, não se restringe ao Brasil. Nas últimas Bienais de Veneza e Berlim aspectos semelhantes foram destacados.

9 Importante colecionador e curador sueco, ajudou a fundar o Centro George Pompidou em Paris e foi seu primeiro diretor. É reconhecido pela inovadora forma com que governou essa instituição de arte, quando expandiu seus limites tradicionais abrindo-a a múltiplas atividades.

Io Walter Zanini dirigiu o Museu de Arte Contemporânea de São Paulo de I963 a I978, realizando grandes transformações no perfil da instituição, incentivando produções artísticas experimentais como videoarte e arte postal. 
I I Frederico Moraes é bastante lembrado pela proposta Domingos de Criação que desenvolveu nos jardins do MAM do Rio de Janeiro em I97I. Nesse evento, artistas e público eram convidados a realizar obras experimentais artísticas, no entorno das estruturas do Museu. Esse episódio é lembrado por seu teor crítico institucional.

I 2 João Luiz Silva Ferreira foi ministro da Cultura de julho de 2008 a dezembro de 20Io, tendo assumido novamente a pasta em 2015 .

I3 Disponível em <http://ultimosegundo.ig.com.br/cultura/ pichacao-volta-a-bienal-pela-porta-da-frente/nI 237666372 888.html>. Acesso em 3 jul. 2015

I4 Disponível em <http://www.culturaemercado.com.br/noticias/juca-ferreia-em-manifesto-no-caso-da-pixacao-dabienal/>. Acesso em 3 jul. 2015

I5 Para uma discussão das políticas do MinC [Ministério da Cultura] a partir do Mídia Tática Brasil, ver Mussi (2014).

I6 Em novembro de 20II, a Hermetic Library relatou em seu blog aumento no número de acessos ao texto de Hakim Bey, associando o acréscimo de downloads às citações do texto por membros do movimento occupy wall street. De fato, a crescente menção ao livreto é visível mundo afora, tanto em movimentos sociais recentes, quanto em trabalhos de jovens artistas. Cf. <http://library.hrmtc. com/20II/Io/o7/hakim-bey-and-the-occupy-wall-streetmovement/>. Acesso em: 3 jul. 2015

I7 Veja-se a arte ambiental de Christo e os prédios envolvidos que se desdobram em desenhos e gravuras capazes de ocupar as galerias.

I8 Em 7 de setembro de 20I4, Daniela Labra, publicou no jornal O Globo o texto "Bienal de Arte de São Paulo - A arte da reflexão", no qual afirma que a mostra possuía "caráter eminentemente político". Além de Labra, Silas Martí, publicou no jornal Folha de S. Paulo, em I de setembro de 20I4, a matéria "Bienal retrata mundo em violenta mutação a partir do olhar de excluídos", no qual demarcou as temáticas discutidas na mostra, como por exemplo: a questão de gênero e os conflitos religiosos.

I9 Disponível em <http://www.3Ibienal.org.br/pt/post/4I I >. Acesso em 3 jul. 2015. 
20 Disponível em <http://www.3rbienal.org.br/pt/post/47I >. Acesso em 3 jul. 2015.

2I Disponível em <http://www.3rbienal.org.br/pt/post/ı998>. Acesso em 3 jul. 2015.

22 Disponível em <http://www.3 Ibienal.org.br/pt/information/754>. Acesso em 3 jul. 2015.

23 Cf. Fôlder da exposição.

24 Cf. Casa Nuvem. Disponível em <https://www.facebook. com/casanuvem/>. Acesso em I jul. 2015.

25 Cf. Olho da Rua. Disponível em <https://www.facebook. com/OlhoDaRuao6/>. Acesso em 2 jul. 2015.

26 Apenas para mencionar alguns exemplos, há espaços como És uma maluca, em Vila Isabel, e a Casa Amarela, na Tijuca, ambos na Zona Norte da cidade, e o Catetegr, no Catete, a X Casa, em Laranjeiras, os dois últimos na Zona Sul. Todos esses espaços se descrevem como espaços colaborativos de criação artística.

27 A esse respeito, diz Benjamin (1985: I83) na primeira versão de "A obra de arte na era de sua reprodutibilidade técnica": "A metamorfose do modo de exposição pela técnica da reprodução é visível também na política. A crise da democracia pode ser interpretada como uma crise nas condições de exposição do político profissional. As democracias expõem o político de forma imediata, em pessoa, diante de certos representantes. O Parlamento é seu público. Mas, como as novas técnicas permitem ao orador ser ouvido e visto por um número ilimitado de pessoas, a exposição do político diante dos aparelhos passa ao primeiro plano. Com isso os parlamentos se atrofiam, juntamente com o teatro". O espelho do valor de exposição seria a sociedade de massas.

28 Pode-se dizer, junto com Adriano Correia (200I: 239), que, para Hannah Arendt, "a esfera pública de legitimidade democrática tem encolhido cada vez mais. [...] O desaparecimento da esfera pública tem como consequência o predomínio de um modelo de sociedade que impõe conformidade e isolamento, o cumprimento de comportamentos predizíveis e o estabelecimento de uma forma burocrática de governo: a sociedade de massas". 


\section{REFERÊNCIAS BIBLIOGRÁFICAS}

Adorno, Theodor. (1998). Museu Valéry Proust. In: Prismas: crítica cultural e sociedade. São Paulo: Ática.

Alexander, Edward P. (I970-I97I). The regional museum as a cultural centre. Museum, Unesco, XXIII/4, p. 274-284.

Arendt, Hannah. (2000). Origens do totalitarismo. São Paulo: Companhia das Letras.

Artivista. (2014). Disponível em <http://pt.wikipedia.org/ wiki/Artivista>. Acesso em I2 jun. 2015.

Benjamin, Walter. (1985). A obra de arte na era de sua reprodutibilidade técnica. In: Obras escolhidas: Magia Técnica e Política. São Paulo: Brasiliense.

Bürger, Peter. (2008). Teoria da vanguarda. São Paulo: Cosac Naify.

Casa Nuvem. Disponível em <https://www.facebook.com/ casanuvem/>. Acesso em I jul. 2015.

Cauquelin, Anne. (2005). Arte contemporânea: uma introdução. São Paulo: Martins Fontes.

Cordeiro, Daphne Assis. (2015). Se essa rua fosse minha...?: performance, arte e ativismo. V Reunião Equatorial de Antropologia (REA) - XIV Reunião de Antropólogos do Norte e Nordeste (Abanne), 20I5, Maceió. Direitos diferenciados, conflitos e produção de conhecimentos. Anais... Maceió: Centro Universitário Tiradentes (Unit), I, p. I-I9. Correia, Adriano. (200I). O desafio moderno: Hannah Arendt e a sociedade de consumo. In: Jardim, Eduardo \& Bignotto, Newton (orgs.). Hannah Arendt: diálogos, reflexões, memórias. Belo Horizonte: Ed. UFMG.

Dabul, Lígia. (2008). Museus de grandes novidades: centros culturais e seu público. Horizontes Antropológicos, Porto Alegre, I4/29, p. 257-278.

De Lucca, Guss. (20Io). Pichação volta à Bienal pela porta da frente. Disponível em <http://ultimosegundo.ig.com.br/ cultura/pichacao-volta-a-bienal-pela-porta-da-frente/ nI237666372888.html>. Acesso em I maio 2013.

Fabbrini, Ricardo Nascimento. (2013). Fim das vanguardas: estetização da vida e generalização do estético. Poliética: Revista de ética e política da Pontifícia Universidade Católica de São Paulo, I, p. I67-I83. 
Fradier, Georges. (1978). The Georges Pompidou National Centre for Art and Culture, Paris. Museum, Unesco, 30/2. Fraser, Andrea. (2005). From the critique of institutions to an institution of critique. Artforum. New York, 44/I, p. 278-283.

Griffing, Robert. (1963). Reflections on the Tokyo Seminar. Museum, Unesco, I6/4.

Habermas, Jürgen. (1984). Mudança estrutural da esfera pública: investigações quanto a uma categoria da sociedade burguesa. Rio de Janeiro: Tempo Presente.

Heinich, Nathalie \& Shapiro, Roberta. (2013). Quando há artificação? Revista Sociedade e Estado, 28/I, p. I4-28.

Huyssen, Andreas. (I997). Memórias do modernismo. Rio de Janeiro: Ed. UFRJ.

Labra, Daniela. (2014). Bienal de Arte de São Paulo - A arte da reflexão. O Globo. Disponível em <http://oglobo. globo.com/cultura/artes-visuais/critica-bienal-de-artede-sao-pauloarte-da-reflexao-I3856635>. Acesso em I5 set. 2015 .

Lima, Daniel. (2015) Copas: I 2 cidades em tensão. Disponível em <http://issuu.com/invisiveisproducoes/docs/livro_copas/I $>$. Acesso em 26 maio 2015.

Marcondes, Guilherme. (20I5). Crítica de arte e a curadoria de exposições: disputas por uma autoridade legitimadora. Revista Em Tese, I2/I, p. 34-63.

Marcondes, Guilherme. (2014). Arte, crítica e curadoria: diálogos sobre autoridade e legitimidade. Dissertação de Mestrado. PPGSA/Universidade Federal do Rio de Janeiro.

Martí, Silas. (2014). Bienal retrata mundo em violenta mutação a partir do olhar de excluídos. Folha de S. Paulo. Disponível em <http://wwwi.folha.uol.com.br/ ilustrada/20I4/og/I508786-bienal-retrata-mundo-emviolenta-mutacao-a-partir-do-olhar-de-excluidos.shtml>. Acesso em I5 set. 2015 .

Miranda, Ana Carolina Freire Accorsi. (2016). Arte e política: autoria coletiva nos anos 2000. Trabalho apresentado na XVII Jornada do Programa de Pós-Graduação em Sociologia e Antropologia. Rio de Janeiro. 
Miranda, Ana Carolina. (20I4). Discursos e práticas: a institucionalização dos coletivos de artistas. Dissertação de Mestrado. PPGCS/Universidade Federal Rural do Rio de Janeiro.

Miranda, Ana \& Sant'anna, Sabrina Parracho. (20I4). Coletivos em performance: algumas relações entre arte, corpo e política. Iluminuras. Porto Alegre, 35, p. 54-79.

Morató, Arturo Rodriguez. (20II). Consensos e controvérsias sobre a cultura na sociologia contemporânea. In: Dwyer, Tom; Villas Bôas, Glaucia \& Scalon, Celi (orgs.). Sociologia: consensos e controvérsias. Porto Alegre: Tomo Editorial, p.Io3-II8.

Mussi, Joana. (20I4). O espaço como obra: ações, coletivos artísticos e cidade. São Paulo: Annablume/Fapesp/Invisíveis Produções.

Obrist, Hans Ulrich. (20I0). Uma breve história da curadoria. São Paulo: BEI Comunicação.

Paola, Fernanda. (2010). Só a arte salva. Disponível em <http://revistacult.uol.com.br/home/201o/og/so-a-artesalva/>. Acesso em I maio 2013.

Provasi, Beatriz. (2014). As guerras nos porta-retratos. Disponível em <http://beatrizprovasi.blogspot.com.br/>. Acesso em I 2 maio 2015.

Raposo, Paulo. (2015). "Artivismo": articulando dissidências, criando insurgências. Cadernos de Antropologia e Arte. Salvador, 4, p. 3-12.

Ribas, Cristina. (2014). Vocabulário político para processos estéticos. Rio de Janeiro: Funarte. Disponível em <http:// vocabpol.cristinaribas.org/wp-content/uploads/20I5/oI/ vocabpol_links-completo.pdf>. Acesso em 25 maio 2015.

Ribeiro, Carolina (20I4). A arte de agregar. Revista O Globo. Rio de Janeiro, II/533.

Sant'anna, Sabrina Parracho. (2012). Memória e modernidade: notas para refletir sobre memória e museus de um ponto de vista sociológico. Panóptica. Vitória, 7, p. 373-389. Sant'anna, Sabrina Parracho. (20I I). Musealização, crítica de arte e o exercício experimental da liberdade em Mário Pedrosa. Estudos Históricos, Rio de Janeiro, 24/48, p. 385404 . 
Sassen, Saskia. (2005). The global city: introducing a concept. The Brown Journal of World Affairs, II/2, p. 27-43.

Silva, Marcelo Kunrath et al. (20I5). Dinâmicas da contestação: transformações nos repertórios de manifestação pública de demandas coletivas no Rio Grande do Sul (I970 e 2010). Anais do $17^{\circ}$ Congresso Brasileiro de Sociologia, Porto Alegre, Brasil.

Szaniecki, Barbara. (2013). Sobre museus e monstros. Na Borda, São Paulo. Disponível em <http://www.naborda. com.br/20I7/08/og/sobre-museus-e-monstros/>. Acesso em 30 nov. 2017.

Zolberg, Vera. (2009). Incerteza estética como novo cânone: os obstáculos e as oportunidades para a teoria em arte. Ciências Humanas e Sociais em Revista, 3I/I, p. 25-40.

Zolberg, Vera \& Cherbo, Joni Maya. (I997). Outsider art: contesting boundaries in contemporary culture. Cambridge: Cambridge University Press. 


\section{Palavras-chave}

Artivismo; arte e política; sociologia da arte; curadoria; crítica de arte.

Keywords

Artivism; art and politics; sociology of arts;

curating; art criticism.

\section{ARTE E POLÍTICA: A CONSOLIDAÇÃO DA ARTE COMO AGENTE NA ESFERA PÚBLICA}

\section{Resumo}

Este artigo se debruça sobre recentes movimentos, constituídos nas cidades do Rio de Janeiro e de São Paulo, que constroem uma narrativa em que performances e instalações vêm ganhando espaço dentro e fora das instituições como formas de atuação política, num crescente processo de "artificação" da esfera pública e politização da arte. Argumentamos que o fracasso da fusão arte e vida tão debatido por Peter Bürger parece ter novos desdobramentos. Mais do que a crítica política à instituição, o que parece estar em jogo é a incorporação da política como terceiro termo capaz de efetivamente conferir novo lugar à arte na esfera pública. Ações artísticas estão sendo incorporadas pelos militantes nas ruas e ações políticas estão sendo apropriadas pelas instituições museais. Dessa forma, nossa hipótese é de que em junho de 2013 inaugura-se no Brasil um movimento de transformação da experiência artística em elemento político.

\section{ART AND POLITICS: THE CONSOLIDATION OF ART AS AN AGENT IN THE PUBLIC SPHERE}

\section{Abstract}

This article aims to discuss recent movements, forged in Rio de Janeiro and São Paulo, that build a narrative in which art performances and installations appear both in and out of art institutions as forms of political action, developing growing processes of artification of the public sphere and the politicization of art. We argue that, perhaps, the failure of the avant-garde project in merging art and life, as discussed by Peter Bürger, can still have further developments. More than institutional critique, the new phenomenon encompasses politics as a third term that enables art to play a new role in the political arena. Artistic actions are being incorporated by militants in the streets and political acts are being appropriated by museum institutions. Thus, our hypothesis is that June 2013 marks the start of a transformational movement in Brazil: artistic experience as political element. 